\title{
PENGARUH BUDAYA ORGANISASI DAN KOMITMEN ORGANISASI TERHADAP ORGANIZATIONAL CITIZENSHIP BEHAVIOR (OCB) PADA PEGAWAI POLITEKNIK ILMU PELAYARAN (PIP) SEMARANG
}

\author{
Moh. Zaenal Arifin \\ Dosen Program Studi Nautika PIP Semarang
}

\begin{abstract}
As for target of which will reach in this research is to analysing cultural influence of organization to PIP Semarang officer Organizational Citizenship Behavior (OCB). Analysing organizational komitmen influence to PIP Semarang officer Organizational Citizenship Behavior (OCB). Pursuant to above mentioned background, hence researcher will test about cultural influence of organizational comitment and organization to officer Organizational Citizenship Behavior (OCB) in is PIP Semarang.

Population in this research is PIP Semarang officer amounting to 319 one who consist of 215 PNS and 104 contract officer. To determine the amount of sample to be used as the source of information in this research is used by Slovin formula. Pursuant to result of calculation of determination of is amount of sampel with Slovin formula hence amount of minimum sampel which needed in this research is 178 PIP Semarang officer responder. Data which is used in research is primary data and secunder. Method analyse data use doubled linear regression analysis.

Pursuant to result of research can be concluded by proven organizational culture have an effect on positively of significant to PIP Semarang officer Organizational Citizenship Behavior $(O C B)$. Its Meaning, if organizational culture as according to individual values hence will push the make-up of employees Organizational Citizenship Behavior (OCB). Proven Organizational Comitment have an effect on positively of significant to PIP Semarang officer Organizational Citizenship Behavior (OCB). Its Meaning, if employees have strong organizational comitment hence this matter will push employees for have high Organizational Citizenship Behavior (OCB)
\end{abstract}

\section{Keywords: cultural of organization, organizational comitment and Organizational Citizenship} Behavior (OCB)

\section{PENDAHULUAN}

Banyak faktor untuk mencapai service quality yang baik bagi penyedia jasa adalah dengan menumbuhkan ketulusan, perasaan senang hati dan timbulnya suatu budaya dimana karyawan akan bekerja sama saling tolong menolong demi memberikan yang terbaik kepada pelanggan (Olorunniwo, et al., 2006). Sikap perilaku karyawan yang dilakukan dengan sukarela, tulus, senang hati tanpa harus diperintah dan dikendalikan oleh perusahaan dalam memberikan pelayanan dengan baik yang menurut Organ et al. (2006) dikenal dengan istilah Organizational Citizenship Behavior (OCB).
Organizational Citizenship Behavior (OCB) selain disebut the extra role behavior (Pearche \& Gregersen, 1991; Wright, 1993) merupakan salah satu kategori yang penting bagi efektifitas organisasi. Hal ini dikemukakan pula oleh Katz (1964) yang mengidentifikasi adanya tiga kategori perilaku pekerja yang penting bagi keefektifan organisasi, yaitu individu harus masuk ke dalam dan tinggal dalam suatu organisasi, mereka harus menyelesaikan peran khusus dalam pekerjaan tertentu, mereka harus terikat pada aktifitas yang inovatif dan spontan melebihi persepsi perannya. Kategori terakhir itulah yang yang disebut sebagai Organizational Citizenship Behavior. 
Moh. Zaenal Arifin

Kesediaan karyawan untuk berperilaku yang mengarah pada OCB atau the extra role behavior tidak dapat dilepaskan dari berbagai faktor yang mempengaruhinya. Untuk dapat meningkatkan OCB karyawan maka sangat penting bagi organisasi untuk mengetahui apa yang menyebabkan timbulnya atau meningkatnya OCB. Menurut Siders et.al. (2001) meningkatnya perilaku OCB dipengaruhi oleh dua faktor utama, yaitu faktor yang berasal dari dalam diri karyawan (internal) seperti moral, rasa puas, sikap positif, dan sebagainya, sedangkan faktor yang berasal dari luar karyawan (eksternal) seperti sistem manajemen, sistem kepeminpinan, budaya perusahaan. Pemahaman akan rancangan kerja dapat membantu para manajer merancang pekerjaan yang secara positif mempengaruhi kinerja pegawai (Robbins, 2006).

Kesediaan karyawan untuk berperilaku yang mengarah pada OCB tidak dapat dilepaskan dari faktor budaya organisasi. Budaya organisasi didefinisikan Furnham dan Gunter (1993) sebagai keyakinan, sikap dan nilai yang umumnya dimiliki yang timbul dalam suatu organisasi. Pola nilai, norma, keyakinan, sikap dan asumsi ini mungkin tidak diungkapkan tetapi akan membentuk cara orang berperilaku dan melakukan sesuatu. Nilai mengacu kepada apa yang diyakini merupakan hal yang penting mengenai cara orang dan organisasi berperilaku.

Selain memperhatikan faktor budaya organisasi, beberapa peneliti beranggapan bahwa perilaku yang mengarah pada OCB tidak dapat dilepaskan dari komitmen pegawai terhadap organisasi karena bagaimanapun prestasi kerja yang melebihi apa yang seharusnya, banyak ditentukan oleh kuat tidaknya komitmen terhadap organisasi (Smith, Organ, \& Near, 1993). Tumbuhnya komitmen tidak dapat muncul begitu saja. Komitmen organisasional merupakan sikap loyalitas seorang pekerja pada suatu organisasi dan hal itu merupakan suatu proses berkelanjutan. Hal-hal yang dapat menumbuhkan komitmen kerja diantaranya adalah kebanggan terhadap organisasi, kepemimpinan, pencapaian tujuan organisasi yang selaras dengan tujuan pegawai serta kesadaran individu akan pentingnya manfaat dari pekerjaan yang dilaksanakannya.

Komitmen organisasional menurut Gibson (1997) adalah identifikasi rasa, keterlibatan loyalitas yang ditampakkan pekerja terhadap organisasi atau unit organisasi. Komitmen organisasional ditunjukkan dalam sikap penerimaan keyakinan yang kuat terhadap nilai-nilai dan tujuan organisasi, dan adanya dorongan yang kuat untuk mempertahankan keanggotaan dalam organisasi demi tercapainya tujuan organisasi. Mowday, Steers, \& Porter (1982) dalam Vandenberg dan Lance (1992) mendefinisikan komitmen organisasional sebagai seberapa jauh tingkat seorang pekerja dalam mengidentifikasikan dirinya pada organisasi serta keterlibatannya di dalam suatu organisasi.

Organisasi yang mampu memberikan perhatian yang penuh dan membuat pegawai percaya terhadap organisasi akan memperoleh komitmen pegawai. Komitmen pegawai terhadap organisasi akan membuat pegawai setia pada organisasi dan bekerja dengan baik untuk kepentingan organisasi (Yuwalliatin, 2006). Keadaan ini sangat baik bagi pencapaian tujuan organisasi karena organisasi mendapat dukungan penuh dari anggotanya sehingga dapat berkonsentrasi secara penuh pada tujan yang diprioritaskan. Morrison (1997) menyatakan bahwa komitmen merupakan faktor yang penting bagi organisasi karena: (1) pengaruhnya bagi turnover dan (2) hubungannya dengan kinerja yang mengasumsikan bahwa individu yang mempunyai komitmen cenderung mengembangkan upaya yang lebih besar pada pekerjaan.

Kajian penelitian mengenai pengaruh budaya organisasi dan komitmen organisasi terhadap Organizational Citizenship Behavior (OCB) akan dilakukan pada pegawai di Politeknik Ilmu Pelayaran Semarang. Politeknik Ilmu Pelayaran Semarang adalah salah satu Lembaga Pendidikan Maritim negeri di bawah naungan Kementerian Perhubungan dan satu-satunya yang berada di 
Jawa Tengah, yang berlokasi di Jalan Singosari 2A Semarang dengan tugas pokok membina dan mencetak lulusan perwiraperwira kapal niaga, baik kapal-kapal milik Negara maupun kapal-kapal swasta

Berdasarkan latar belakang tersebut di atas, maka peneliti akan menguji tentang pengaruh budaya organisasi dan komitmen organisasi terhadap Organizational Citizenship Behavior (OCB) pada pegawai Politeknik Ilmu Pelayaran Semarang.

\section{METODE PENELITIAN}

\section{A. Jenis Penelitian}

Penelitian ini merupakan explanatory research dengan pendekatan kausalitas, yaitu penelitian yang ingin mencari penjelasan dalam bentuk hubungan sebab akibat (cause-effect) antar beberapa konsep atau beberapa variabel atau beberapa strategi yang dikembangkan dalam manajemen (Ferdinand, 2006).

Populasi dalam penelitian ini adalah pegawai PIP Semarang yang berjumlah 319 orang. Sampel adalah sebagian dari populasi yang memiliki karakteristik yang relatif sama dan dianggap bisa mewakili populasi (Singarimbun, 1991). Untuk menentukan jumlah sampel yang akan digunakan sebagai sumber informasi dalam penelitian ini digunakan rumus Slovin (Supramono, 2004). Berdasarkan hasil perhitungan penentuan jumlah sampel dengan rumus Slovin maka jumlah sampel minimal yang diperlukan dalam penelitian ini adalah 178 responden pegawai PIP Semarang.

\section{B. Teknik Pengambilan Sampel}

Adapun teknik pengambilan sampel yang digunakan dalam penelitian ini adalah Simple Random Sampling dimana tiap anggota populasi memiliki kesempatan yang sama untuk terpilih menjadi sampel penelitian.

\section{Metode Pengumpulan Data}

Untuk mengumpulkan data penelitian, kuesioner dipilih sebagai metode pengumpulan data dalam penelitian ini. Kuesioner adalah daftar pertanyaan tertulis yang telah dirumuskan sebelumnya yang akan dijawab oleh responden. Kuesioner dipilih karena merupakan suatu mekanisme pengumpulan data yang efisien untuk mengetahui dengan tepat apa yang diperlukan dan bagaimana mengukur variabel penelitian (Sekaran, 2006).

Tipe pertanyaan dalam kuesioner adalah pertanyaan tertutup dimana responden diminta untuk membuat pilihan diantara serangkaian alternatif yang diberikan oleh peneliti (Sekaran, 2006). Skala data jawaban responden atas pertanyaan penelitian dengan menggunakan Agree-Disagree Scale yang menghasilkan jawaban sangat tidak setujujawaban sangat setuju dalam rentang nilai $1 \mathrm{~s} / \mathrm{d} 7$ (Ferdinand, 2006).

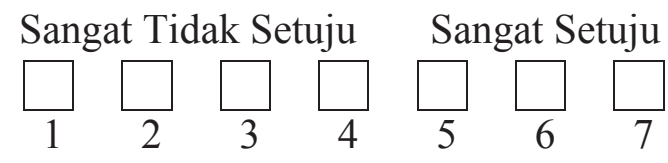

Data yang diperlukan dalam penelitian ini, diperoleh melalui dua sumber, yaitu (Sekaran, 2006):

1. Data primer

Data primer yang diperoleh dalam penelitian ini adalah data tentang karakteristik demografik responden (jenis kelamin, pendidikan, usia, dan masa kerja), budaya organisasi, komitmen organisasi dan kinerja pegawai.

2. Data sekunder

Data sekunder yang diperoleh dalam penelitian ini adalah data tentang gambaran umum PIP Semarang dan daftar nama pegawai.

\section{Variabel Budaya Organisasi}

Variabel budaya organisasi yang diteliti dalam penelitian ini diukur dengan menggunakan indikator yang dikembangkan dari penelitian Hofstede (1994) yaitu mengutamakan keputusan yang diambil karyawan, kepedulian pada masalah karyawan, memberikan petunjuk, mengutamakan hasil yang dicapai karyawan. 

(OCB) pada Pegawai Politeknik Ilmu Pelayaran (PIP) Semarang

Moh. Zaenal Arifin

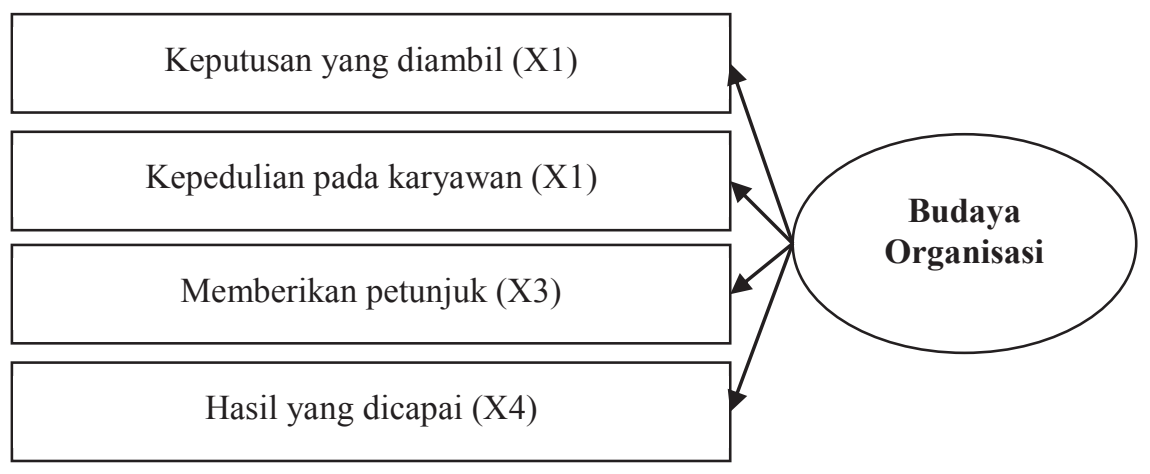

Gambar Indikator Variabel Budaya Organisasi

\section{E. Variabel Komitmen Organisasi}

Variabel komitmen organisasi yang diteliti dalam penelitian ini diukur dengan menggunakan indikator yang dikembangkan oleh Luthans (2006), yaitu keinginan kuat untuk tetap sebagai anggota organisasi tertentu, keinginan untuk berusaha keras sesuai keinginan organisasi, keyakinan tertentu pada nilai organisasi, dan penerimaan tujuan organisasi.

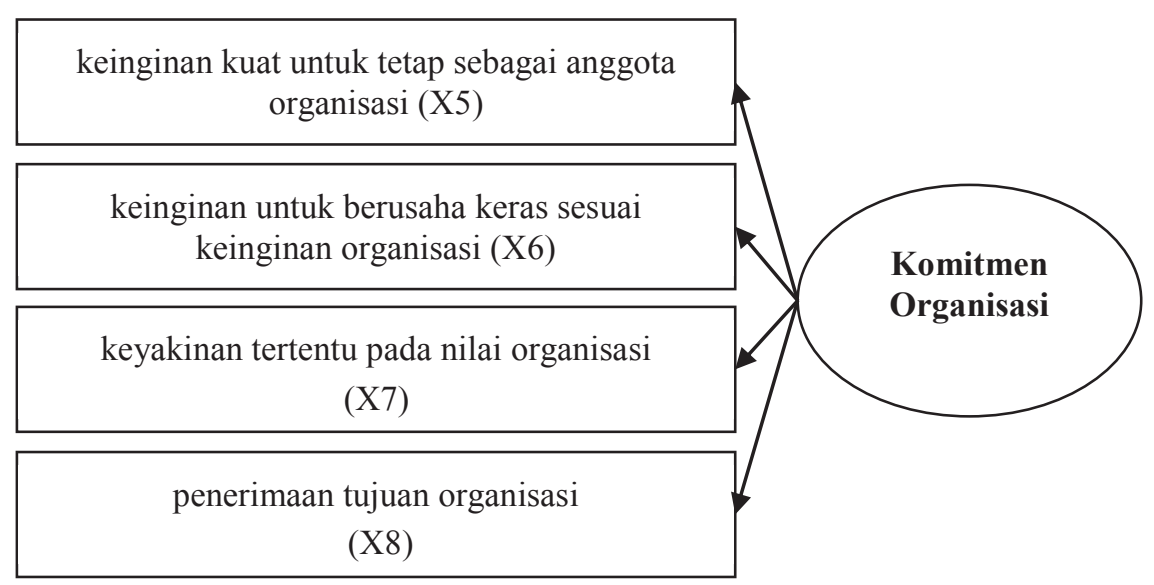

Gambar Indikator Variabel Komitmen Organisasi
F. Variabel Organizational Citizenship dikembangkan oleh Organ (1998) dan Behavior (OCB)
Variabel OCB yang diteliti dalam penelitian ini diukur dengan menggunakan indikator yang Allison et al (2001), yaitu altruism, civic virtue, conscientiousness, courtesy, dan sportsmanship.




\section{G. Indikator Variabel Organizational Citizenship Behavior (OCB)}

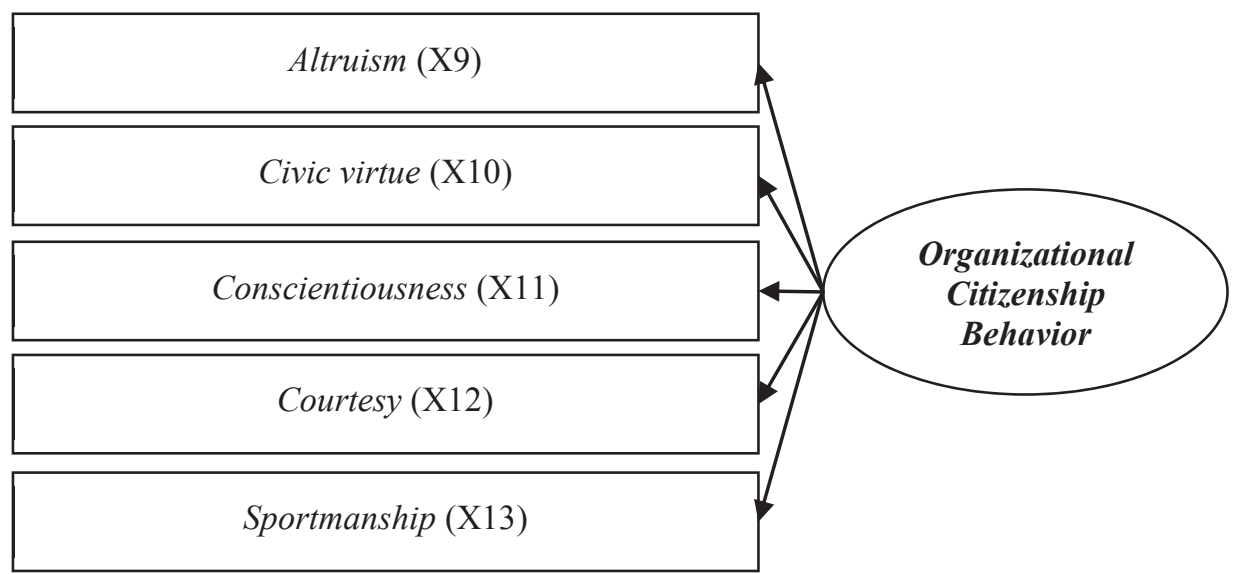

Gambar Indikator Variabel Organizational Citizenship Behavior (OCB)

\section{H. Teknik Analisis}

Untuk menganalisis data yang diperoleh melalui kuesioner.

\section{Analisis Deskriptif}

Analisis ini dilakukan untuk mendapatkan gambaran mengenai jawaban responden mengenai variabelvariabel penelitian yang digunakan. Analisis ini dilakukan dengan menggunakan teknik Analisis Indeks, untuk menggambarkan persepsi responden atas item-item pertanyaan yang diajukan.

\section{Uji Kualitas Data}

\section{a) Uji Validitas}

Validitas menunjukkan tingkat kemampuan suatu instrument untuk mengungkapkan sesuatu yang menjadi sasaran pokok pengukuran yang dilahirkan dengan instrument tersebut (Hadi, 2002). Untuk menguji validitas digunakan uji Korelasi Product Moment dengan kriteria pengujian sebagai berikut:

- Jika nilai $r$ hitung $>\mathrm{r}$ tabel dan nilai signifikansi $<0,05$ maka dapat dikatakan bahwa indikator adalah valid

- Jika nilai $\mathrm{r}$ hitung $<\mathrm{r}$ tabel dan nilai signifikansi $>0,05$ maka dapat dikatakan bahwa indikator tidak valid

\section{b) Uji Reliabilitas}

Reliabilitas menunjukkan sejauh mana suatu instrument dapat memberikan hasil pengukuran yang konsisten. Pengujian reliabilitas dilakukan dengan menggunakan Uji Alpha Cronbach dengan kriteria hasil pengujian sebagai berikut:

- Jika nilai Alpha Cronbach hasil perhitungan $>0,6$ maka dapat dikatakan bahwa variabel penelitian adalah reliabel

- Jika nilai Alpha Cronbach hasil perhitungan $<0,6$ maka dapat dikatakan bahwa variabel penelitian tidak reliabel

\section{Uji Asumsi Klasik}

Uji asumsi klasik adalah uji yang dilakukan untuk menganalisis asumsiasumsi dasar yang harus dipenuhi dalam penggunaan regresi. Uji asumsi klasik ini bertujuan agar menghasilkan estimator linear tidak bias yang terbaik dari model regresi yang diperoleh dari metode kuadrat terkecil. Dengan terpenuhinya asumsi-asumsi tersebut maka hasil yang diperoleh dapat lebih akurat dan mendekati atau sama dengan kenyataan (Hasan, Iqbal, 2002). Adapun asumsi-asumsi klasik yang dilakukan dalam penelitian ini meliputi (Ghozali, Imam, 2001): 


\section{a) Uji Normalitas}

Bertujuan untuk menguji apakah dalam model regresi, variabel terikat dan variabel bebas, keduanya mempunyai distribusi normal ataukah tidak. Uji normalitas dilakukan terhadap residu data penelitian dengan menggunakan uji Kolmogorov Smirnov. Pengujian normalitas data dilakukan dengan kriteria sebagai berikut:

- Jika nilai signifikansi > 0,05 maka dapat disimpulkan bahwa distribusi residual data penelitian adalah normal

- Jika nilai signifikansi $<0,05$ maka dapat disimpulkan bahwa distribusi residual data penelitian tidak normal

\section{b) Uji Multikolinieritas}

Bertujuan untuk menguji apakah model regresi ditemukan adanya korelasi antar variabel bebas (independent). Untuk mengetahui ada atau tidaknya multikolinieritas dalam model regresi dilakukan dengan melihat nilai Variance Inflation Factor (VIF) dan tolerance dengan ketentuan sebagai berikut (Ghozali, Imam, 2001):

- Jika nilai VIF > 10 maka dapat disimpulkan bahwa dalam persamaan regresi terdapat masalah multikolinieritas

- Jika nilai VIF $<10$ maka dapat disimpulkan bahwa dalam persamaan regresi tidak terdapat masalah multikolinieritas

\section{c) Uji Heteroskedastisitas}

Bertujuan untuk menguji apakah dalam model regresi terjadi ketidaksamaan variance dari residual satu pengamatan ke pengamatan yang lain. Untuk menganalisis terjadinya masalah heteroskedastisitas, dilakukan dengan dengan Uji Glejser dengan kriteria sebagai berikut:

- Jika nilai signifikansi masingmasing variabel bebas terhadap nilai Absolut Residual adalah $>0,05$ maka dapat diartikan bahwa data penelitian tidak terdapat masalah heteroskedastisitas

- Jika nilai signifikansi masingmasing variabel bebas terhadap nilai Absolut Residual adalah $<0,05$ maka dapat diartikan bahwa data penelitian terdapat masalah heteroskedastisitas.

\section{Uji Regresi}

Metode regresi berganda ini dikembangkan untuk mengestimasi nilai variabel dependen (Y) dengan menggunakan lebih dari satu variabel independen (X). Adapun persamaan regresinya adalah sebagai berikut:

$$
\mathbf{Y}=\boldsymbol{\beta}_{1} \mathbf{X}_{1}+\boldsymbol{\beta}_{2} \mathbf{X}_{\mathbf{2}}+\mathrm{e}
$$

Keterangan:

$$
\begin{array}{ll}
\mathrm{Y} & =\begin{array}{l}
\text { Organizational Citizenship } \\
\text { Behavior }(\mathrm{OCB})
\end{array} \\
\mathrm{X}_{1} & =\text { Budaya organisasi } \\
\mathrm{X}_{2} & =\text { Komitmen organisasi } \\
\alpha & =\text { Konstanta } \\
\beta_{1}, \beta_{2} \cdot= & \text { Koefisien Regresi } \\
\mathrm{e} & =\text { Error }
\end{array}
$$

a) Penguin Hipotesis secara Parsial (Uji t)

Untuk mengetahui ada tidaknya pengaruh variabel bebas terhadap variabel terikat maka dilakukan pengujian terhadap hipotesis yang akan diajukan pada penelitian ini. Metode pengujian terhadap hipotesis dilakukan secara parsial dengan menggunakan uji t dengan kriteria sebagai berikut:

- Jika nilai t hitung $>\mathrm{t}$ tabel atau nilai signifikansi $<0,05$ maka dapat disimpulkan bahwa variabel independen terbukti secara statistik berpengaruh terhadap variabel dependen.

- Jika nilai t hitung $<\mathrm{t}$ tabel atau nilai signifikansi $>0,05$ maka dapat disimpulkan bahwa variabel independen tidak terbukti secara statistik berpengaruh terhadap variabel dependen. 


\section{b) Uji Kelayakan Model}

Uji ini dilakukan untuk melihat apakah model yang dianalisis memiliki tingkat kelayakan model yang tinggi yaitu variabel-variabel yang digunakan model mampu untuk menjelaskan fenomena yang dianalisis. Untuk menguji kelayakan model penelitian ini digunakan Uji Anova (uji F) dengan kriteria sebagai berikut:

- Jika nilai $\mathrm{F}$ hitung $>\mathrm{F}$ tabel atau nilai signifikansi $<0,05$ maka dapat disimpulkan bahwa seluruh variabel independen yang diuji merupakan variabel yang tepat dalam memprediksi variabel dependen

- Jika nilai $\mathrm{F}$ hitung $<\mathrm{F}$ tabel atau nilai signifikansi $>0,05$ maka dapat disimpulkan bahwa seluruh variabel independen yang diuji merupakan variabel yang tidak tepat dalam memprediksi variabel dependen c) Koefisien Determinasi

$\begin{array}{ccc}\text { Koefisien } & \text { determinasi } & (\mathrm{R} 2) \\ \text { menunjukkan } & \text { seberapa } & \text { besar }\end{array}$ kemampuan model (variabel independen) dalam menerangkan variasi variabel dependen. Dimana nilai $\mathrm{R}^{2}$ berkisar antara $0<\mathrm{R}^{2}<1$, artinya :

- Jika nilai R2 semakin mendekati nol berarti kemampuan variabel bebas dalam menjelaskan variasi pada variabel terikatsemakin kecil.

- Jika nilai R2 semakin mendekati satu berarti kemampuan variabel bebas dalam menjelaskan variasi pada variabel terikat semakin besar.

\section{HASIL DAN DISKUSI}

Pengujian persamaan dilakukan dengan menggunakan Uji Regresi Berganda yang terdiri atas tiga tahap analisis yang harus dilakukan, yaitu uji signifikansi parsial, uji kelayakan model, dan analisis nilai koefisien determinasi. Berikut ini uraian hasil pengujian terhadap persamaan regresi.

Tabel Uji Regresi Berganda Pengaruh Budaya Organisasi dan Komitmen Organisasi Terhadap Organizational Citizenship Behavior (OCB)

\begin{tabular}{lllll}
\hline \multicolumn{5}{l}{ Variabel Terikat: Organizational Citizenship Behavior (OCB) } \\
\hline Variabel Bebas & $\begin{array}{l}\text { Unstandardized } \\
\text { Coeff }\end{array}$ & $\begin{array}{l}\text { Standardized } \\
\text { Coeff }\end{array}$ & $\mathbf{t}$ & Sig \\
\hline Konstanta & 4,419 & & 1,973 &, 050 \\
Budaya Organisasi &, 575 &, 645 & 11,570 &, 000 \\
Komitmen Organisasi &, 487 &, 305 & 5,477 &, 000 \\
F Hitung & 75,585 & & & \\
Signifikansi F Hitung & 0,000 & & & \\
Adjusted R Square & 0,457 & & & \\
\hline
\end{tabular}

Sumber: Data Primer yang Diolah, 2016

\section{Uji Signifikansi Parsial}

Pengujian terhadap kedua hipotesis yang diajukan dalam penelitian ini dilakukan dengan menggunakan Uji $\mathrm{t}$ dengan kriteria sebagai berikut:

a. Jika nilai t hitung $>\mathrm{t}$ tabel pada $\mathrm{df}(\mathrm{n}$ $1=177$ dan $\alpha=5 \%$ ) =1,973 atau nilai signifikansi $<0,05$ maka dapat disimpulkan bahwa variabel independen terbukti secara statistik berpengaruh terhadap variabel dependen

b. Jika nilai $\mathrm{t}$ hitung $<\mathrm{t}$ tabel pada df ( $\mathrm{n}$ $1=177$ dan $\alpha=5 \%)=1,973$ atau nilai signifikansi $>0,05$ maka dapat disimpulkan bahwa variabel independen tidak terbukti secara 
statistik berpengaruh terhadap variabel dependen.

Mengacu pada output SPSS di atas maka dapat dilakukan pengujian atas hipotesis penelitian sebagai berikut:

\section{1) Pengujian Pengaruh Budaya Organisasi terhadap OCB}

Pengujian ada tidaknya pengaruh budaya organisasi terhadap OCB yang menghasilkan koefisien regresi sebesar 0,645 , t hitung sebesar 11,570, dan nilai signifikansi sebesar 0,000 . Oleh karena nilai $\mathrm{t}$ hitung $>$ nilai $\mathrm{t}$ tabel $(1,973)$ dan nilai signifikansi $<0,05$ maka dapat disimpulkan bahwa budaya organisasi terbukti berpengaruh positif signifikanterhadap OCB.

\section{2) Pengujian Pengaruh Komitmen Organisasi terhadap OCB}

Pengujian ada tidaknya pengaruh komitmen organisasi terhadap OCB yang menghasilkan koefisien regresi sebesar 0,305, t hitung sebesar 5,477, dan nilai signifikansi sebesar 0,000 . Oleh karena nilai $\mathrm{t}$ hitung $>$ nilai $\mathrm{t}$ tabel $(1,973)$ dan nilai signifikansi < 0,05 maka dapat disimpulkan bahwa komitmen organisasi terbukti berpengaruh positif signifikanterhadap OCB.

Berdasarkan hasil pengujian yang dilakukan terhadap variabel budaya organisasi, komitmen organisasi, dan OCB maka dapat dirumuskan persamaan regresi bergandanya sebagai berikut:

$$
\begin{aligned}
& \mathbf{Y = 0 , 6 4 5} \mathbf{X}_{\mathbf{1}}+\mathbf{0 , 3 0 5} \mathbf{X}_{\mathbf{2}} \\
& \text { Dimana: } \\
& Y \quad=\text { OCB } \\
& \mathrm{X}_{1} \quad=\text { Budaya organisasi } \\
& \mathrm{X}_{2} \quad=\text { Komitmen Organisasi }
\end{aligned}
$$

Dengan menggunakan persamaan regresi pada model regresi berganda di atas maka dapat diuraikan sebagai berikut:

a. $\beta_{1}=0,645 \rightarrow \beta_{1}$ bertanda positif menunjukkan besarnya pengaruh budaya organisasi terhadap OCB yang berarti bahwa bila budaya organisasi ditingkatkan maka perilaku OCB karyawan di Politeknik Ilmu Pelayaran (PIP) Semarang juga akan meningkat.

b. $\beta_{2}=0,305 \rightarrow \beta_{2}$ bertanda positif menunjukkan besarnya pengaruh komitmen organisasi terhadap OCB yang berarti bahwa bila komitmen organisasi ditingkatkan maka perilaku OCB karyawan di Politeknik Ilmu Pelayaran (PIP) Semarang juga akan meningkat.

\section{Uji Kelayakan Model}

Uji kelayakan model dilakukan untuk mengetahui apakah variabel-variabel yang diteliti dalam penelitian ini memiliki tingkat kelayakan yang tinggi untuk dapat menjelaskan fenomena yang dianalisis. Pengujian kelayakan model dilakukan dengan menganalisis nilai signifikansi dari Uji F yaitu sebesar 0,000 yang kurang dari $\alpha$ (0.05). Hal ini menunjukkan bahwa variabel independen yang digunakan, yaitu budaya organisasi dan komitmen organisasi merupakan variabel yang tepat/layak untuk menjelaskan terjadinya variasi dalam variabel OCB.

\section{Koefisien Determinasi}

Analisis terhadap nilai koefisien determinasi dilakukan untuk mengetahui seberapa besar kemampuan variabel independen dalam menjelaskan variasi yang terjadi dalam variabel dependen.Koefisien determinasi yang digunakan dalam penelitian ini adalah nilai Adjusted $\mathrm{R}$ Square yaitu sebesar 0,457 atau sebesar 45,7\%. Hal ini menunjukkan bahwa variabel independen (budaya organisasi dan komitmen organisasi) mampu menjelaskan variasi yang terjadi pada OCB sebesar 45,7\%.

\section{- Pengaruh Budaya Organisasi terhadap OCB}

Dari penelitian yang telah dilakukan dapat disimpulkan bahwa hipotesis yang menyatakan bahwa budaya organisasi berpengaruh positif terhadap OCB karyawan PIP Semarang dapat diterima. 
Budaya organisasional merupakan suatu sistem dari kepercayaan-kepercayaan dan nilai-nilai bersama dalam organisasi dan mengarahkan perilaku anggotanya, dan pada akhirnya menghasilkan norma perilaku. Hal ini berarti bahwa ketika budaya yang ada di dalam organisasi ini semakin baik atau kondusif untuk bekerja maka akan meningkatkan OCB karyawan. Dengan demikian penelitian ini mendukung penelitian yang dilakukan oleh Shofiyannah (2008) bahwa budaya organisasi memiliki pengaruh yang erat terhadap OCB. Demikian pula dengan penelitian yang dilakukan oleh Hardaningtyas (2005), Rini, Rusdarti dan Suparjo (2013), Purnama (2013) dan Mohanty dan Rath (2012) yang juga menunjukkan adanya pengaruh positif dan signifikan dari budaya organisasi terhadap OCB.

\section{- Pengaruh Komitmen Organisasi terhadap OCB}

Hasil penelitian ini menunjukan bahwa hipotesis yang berbunyi komitmen organisasi berpengaruh positif terhadap OCB karyawan PIP Semarang dapat diterima. Komitmen organisasional merujuk pada sikap untuk tetap sebagai anggota organisasi tertentu, keinginan untuk berusaha keras sesuai keinginan organisasi, keyakinan tertentu dan penerimaan nilai dan tujuan organisasi. Komitmen seringkali dianggap sebagai salah satu faktor yang paling umum digunakan untuk mengukur perilaku dalam perspektif psikologi organisasi.

Hasil studi empiris (Mowday, Steers, dan Porter, 1979; Mathieu dan Zajac, 1990; Benkhoff, 1997; Somers, 1995; Lum et al, 1998) menunjukkan hubungan yang positif antara komitmen organisasi dan berbagai hasil yang diinginkan dalam organisasi. Demikian pula penelitian yang dilakukan oleh Syihabudhin (2008), Debora Eflina Purba dan Liche Seniati (2004), Ferry Novliadi (2007), Rini, Rusdarti dan Suparjo (2013), dan Purnama (2013) juga menunjukkan bahwa komitmen organisasional merupakan anteseden yang berpengaruh signifikan terhadap

organizational citizenship behavior.

\section{KESIMPULAN}

1. Budaya organisasi terbukti berpengaruh positif signifikan terhadap OCB karyawan PIP Semarang. Artinya, jika budaya organisasi semakin baik maka akan meningkatkan perilaku OCB karyawan PIP Semarang.

2. Komitmen organisasi terbukti berpengaruh positif signifikan terhadap OCB karyawan PIP Semarang. Artinya jika karyawan memiliki komitmen yang kuat pada organisasinya maka akan meningkatkan perilaku OCB karyawan PIP Semarang.

\section{DAFTAR PUSTAKA}

Aldag, RJ, SH Barr, AP Brief. 1981. "Measurement of Perceived Task Characteristics", Psychological Bulletin, Vol. 90, p. 415 - 431

Allison, J Barbara., S Richard Voss, Richard C. 2001. An Empirical Investigation of The Impact of SDB on The Relationship Between OCB and Individual Performance, http://www.sbaer.uca.edu/research/ 2001/ACME/16lacme01.htm

Arikunto, Suharsimi. 1995. Prosedur Penelitian suatu Pendekatan Praktek. Jakarta: Rineka Cipta

As'ad. 1998. Psikologi Industri. Yogyakarta: Penerbit Liberty

Babakus, E, DW Cravens, K Grant, TN Ingram, RW LaForge. 1996. "Investigating The Relationship Among Sales Management Control, Sales Territory Design, Salesperson Performance and Sales Organization Effectivenss", International Journal of Research in Marketing, Vol. 13, p. $345-363$ 
Pengaruh Budaya Organisasi dan Komitmen Organisasi terhadap Organizational Citizenship Behavior (OCB) pada Pegawai Politeknik Ilmu Pelayaran (PIP) Semarang

Moh. Zaenal Arifin

Beker, T.E dan R.J Klimoski. 1999. Field Study of the Relationship Between the Organizational Feedback Environment and Performance, Journal of PersonneelPsychology, $42,343-358$

Benkhoff, B. 1997. Ignoring Commitment Is Costly: New Approaches Establish the Missing Link Between Commitment and Performance, Human Relations, 50 (6), 701-726

Boorman, Walter C. 2004. The Concept of Organizational Citizenship, Current Directions in Psychological Science, 13 (6), 238-241

Borman, WC dan SJ Motowidlo. 1993. Expanding The Criterion Domain to Include Elements of Extra-role Performance, Personnel Selection in Organization. San Fransisco: Jossey - Bass

Brahmasari, I.A \& A. Suprayetno. 2008. Pengaruh Motivasi Kerja, Kepemimpinan dan Budaya Organisasi Terhadap Kepuasan Kerja Karyawan serta Dampaknya pada Kinerja Perusahaan (Studi kasus pada PT. Pei Hai International Wiratama Indonesia), Jurnal Manajemen dan Kewirausahaan, 10 (2), 124-135.

Byars dan Rue. 1984. Manajemen Sumber Daya Manusia. Yogyakarta: Andi Offset

Byars. 2001. Manajemen Sumber Daya Manusia. Yogyakarta: Andi

Cheng, Yuan \& Arne L. Kalleberg. 1996. Employee Job Performance in Britain and The United States

Purba, Debora Eflina dan Liche Seniati. 2004. Pengaruh Kepribadian dan Komitmen Organisasi terhadap Organizational Citizenship Behavior, Makara Sosial Humaniora, Vol. 8 No. 3, p. 105-111
Dyne, LV, JW Graham, RM Dienesch. 1994. "Organizational Citizenship Behavior: Construct Redefinition, Measurement, and Validation", Academy of Management Journal, Vol. 37 No. 4, p. $765-802$

Elizur, Dov dan Meni Koslowsky. 2001. "Values and Organizational Commitment", International Journal of Manpower, Vol. 22 No. 7-8., p. 593-599

Ferdinand, Augusty. 2006. Metode Penelitian Manajamen. Semarang: Badan Penerbit Universitas Diponegoro

Ferry Novliad. 2007. "Organizational Citizenship Behavior Karyawan Ditinjau Dari Persepsi terhadap Kualitas Interaksi Atasan Bawahan dan Persepsi terhadap Dukungan Organisasional”, USU Repository, USU, Tidak Dipublikasikan

Flippo, Edwin B. 1994. Manajemen Personalia. Jakarta: Penerbit Erlangga

Ghozali, Imam. 2001. Aplikasi Analisis Multivariate Dengan Program SPSS. Semarang: Badan Penerbit Universitas Diponegoro

Gibson, Donnely. 1997. Organisasi: Perilaku, Struktur dan Proses. Jakarta

Greenberg, Jerald \&R.A Baron. 2000. Behavior in Organizations: Understanding and Managing The Human Side of Work. New Jersey: Prentice Hall International

Hadi, Sutrisno. 2002. Metodologi Research. Yogyakarta: Andi Offset 
Hardaningtyas, Dwi. 2005. Pengaruh Tingkat Kecerdasan Emosi dan Sikap pada Budaya Organisasi terhadap Organizational Citizenship Behavior (OCB) Pegawai PT. (Persero) Pelabuhan Indonesia III, Thesis Universitas Airlangga Surabaya, (http://www.damandiri.or.id), [Online]

Hasan, Iqbal. 2002. Pokok-Pokok Metodologi Penelitian dan Aplikasinya. Bogor: Ghalia

Hofstede. 1994. Measuring Organizational Cultures: A Qualitative and Quantitative Study Across Twenty Cases. Administrative Science Quarterly, 35, 286-316

Ivancevich, J.M., Gibson J.L. \& Donnely James H. 1993. Organisasi, Perilaku, Struktur, Proses. Jakarta: Erlangga

Kast, Fremon E. \& James E. Rosenweig. 1990. Organisasi dan Manajemen. Jakarta: Bumi Aksara

Kotter, J.P. dan J.L. Hesket. 1999. Corporate Culture and Performance. Jakarta: Prenhallindo

Lum et. al. 1998. Explaining Nursing Turnover Intent: Job Satisfaction, Pay Satisfaction,or Organizational Commitment?, Journal of Organizational Behaviour, 19 (3),305-320

Luthans, Fred. 2006. Perilaku Organisasi, $10^{\text {th }}$ ed. Yogyakarta: Andi

Mas'ud, Fuad. 2004. Survai Diagnosis Organisasional: Konsep dan Aplikasi. Semarang : BP Undip

Mathieu, J.E dan Zajac, D.M. 1990. A Review and Meta Analysis of the Antecedents, Correlates, Consequences of Organizational Commitment, Psychological Bulletin, 108, 171-194

McCormick dan Tiffin. 1994. On Strategic Net Works, Strategic Management Journal, Vol. 9 No. 31-41
Meyer, John P, Natalie J Allen \& Catherina A Smith. 1993. Commitment to Organizational and Occupation: Extention and Test of a Three Component Conceptualization, Journal Applied Psychology, Vol. 78. No.4

Culture on Organizational Citizenship Behavior: A Three-Sector Study, Global Journal of Business Research, 6 (1)

Morrison, E.W. 1997. Role Definitions and Organizational Citizenship Behavior: The Importance of The Employee's Perspective, Academy of Management Journal, 37, 15431567

Mowday, RT, LW Porter, and RM Steers. 1982. Emploee Organization Linkage: The Psychology of Commitment, Abseintism, and Turnover. London Academin Press

Murty, Windy Aprilia dan Gunasti Hudiwinasih. 2012. Pengaruh Kompensasi, Motivasi dan Komitmen Organisasional terhadap Kinerja Karyawan Bagian Akuntansi (Studi Kasus Pada Perusahaan Manufaktur Di Surabaya), The Indonesian Accounting Review, 2 (2)

Nyhan. 1999. Building Learning Organisations; Putting Theory to Test: Lessonsfrom European Companies, In European Journal of Vocational Training

Olorunniwo, F., Hsu, M. K., \& Udo, G. J. 2006. Service Quality, Customer Satisfaction, and Behavioral Intention in the Service Factory, The Journal of Service Marketing, 20 (1), 59-72.

Organ, DW. 1988. Organizational Citizenship Behavior : The Good Soldier Syndrome, Lexington, MA: Lexington Books 
Pengaruh Budaya Organisasi dan Komitmen Organisasi terhadap Organizational Citizenship Behavior (OCB) pada Pegawai Politeknik Ilmu Pelayaran (PIP) Semarang

Moh. Zaenal Arifin

Organ, DW. 1997. Organizational Citizenship Behavior: It's Construct Clean-up Time, Human Performance, Vol. 10, p. 85 -97

Podsakoff \& SB McKenzie. 2000. Organizational Citizenship Behavior and Sales Unit Effectiveness, Journal of Marketing Research, Vol. 31, p. 351 - 363

Purnama, Chamdan. 2013. Influence Analysis of Organizational Culture Organizational Commitment Job and Satisfaction Organizational Citizenship Behavior (OCB) Toward Improved Organizational Performance, International Journal of Business, Humanities and Technology, 3(5)

Rini, Dyah Puspita., Rusdarti dan Suparjo. 2013. Pengaruh Komitmen Organisasi, Kepuasan Kerja Dan Budaya Organisasi Terhadap Organizational Citizenship Behavior (OCB) (Studi pada PT. Plasa Simpanglima Semarang), Jurnal Ilmiah Dinamika Ekonomi Dan Bisnis, 1 (1)

Robbins , Stephen P. 2006. Perilaku Organisasi. Jakarta: PT. Indeks Gramedia

Sekaran, Uma. 2006. Research Methods For Business. Jakarta: Penerbit Salemba Empat

Seymour, Muchinsky PM. 1985. Job Satisfaction and Job Performance: A Meta Analysis, Psychological Bulletin, Vol. 97., p. 251-273

Simamora, Henry. 2004. Manajemen Sumber Daya Manusia. Yogyakarta: Penerbit Bag. Penerbitan. STIE YKPN

Singarimbun, Masri \& Sofyan Effendi. 1991. Metode Penelitian Survai. Jakarta : LP3ES
Soedjono. 2005. Pengaruh Budaya Organisasi Terhadap Kinerja Organisasi dan Kepuasan Kerja Karyawan pada Terminal Penumpang Umum di Surabaya, Jurnal Manajemen dan Kewirausahaan, 7 (1)

Steers, Richard M. 1985. Efektifitas Organisasi : Penerbit Erlangga

Supramono dan Intiyas Utami. 2004. Desain Proposal Penelitian Akuntansi dan Keuangan, Yogyakarta: Penerbit Andi

Syihabudhin. 2008. Faktor-Faktor yang Mempengaruhi Komitmen Organizational dan Organizational Citizenship Behavior (Studi pada Karyawan Sektor Industri Ritel Modern di Malang - Jawa Timur), Tesis, Unair, Tidak Dipublikasikan

Tintri, Dharma. 2002. Pengaruh Struktur dan Kultur Organisasional terhadap Keefektifan Anggaran Partisipatif dalam Meningkatkan Kinerja Manajerial, Jurnal Ekonomi dan Bisnis, 2 (7)

Vandenberg, R.J., and Lance, C.E. 1992. Examining the Central Order of Job Satisfaction and Organizational Commitment, Journal of Management, 18, 53-167

Verawati, Yenny dan Joko Utomo. 2012. Pengaruh Komitmen Organisasi, Partisipasi dan Motivasi terhadap Kinerja Karyawan pada PT. Bank Lippo Tbk Cabang Kudus, Analisis Manajemen, 5 (2)

William, L dan J. Hazer. 1986. Antecedents and Consequences of Satisafaction and Commitmen in Turnover Model : A Reanalysis Using Latent Variable Structural Eqaution Modeling, Journal of Applied Psychology, No. 71, p. $219-231$ 
Wirda, Fisla dan Tuti Azra. 2007. Pengaruh

Budaya Organisasi terhadap Kinerja Karyawan Politeknik Negeri Padang, Jurnal Ekonomi dan Bisnis, 2 (1)

Yuwalliatin, Sitty. 2006. Pengaruh Budaya Organisasi, Motivasidan Komitmen Terhadap Kinerja Serta Pengaruhnya Terhadap Keunggulan Kompetitif Dosen Unissula Semarang, Jurnal Ekonomi dan Bisnis, Vol. 7 No. 2, Juli, 241-256 